\title{
Design and Development of Energy Efficient Eco Friendly Wooden Casing Led based Solar Lantern for Rural Area
}

\author{
Rajesh M. Dharaskar*, A.G. Mohod, R.U. Sawant, N.A. Sail and P.R. Kolhe
}

College of Agricultural Engineering and Technology, Dr. Balasaheb Sawant Konkan Krishi Vidyapeeth, Dapoli, Dist- Ratnagiri, Maharashtra, India

*Corresponding author

\section{Keywords}

Solar Panel, LED, Charge Controller, Battery

Article Info

Accepted:

15 January 2019

Available Online:

10 February 2019

\section{A B S T R A C T}

Load shading is one of the major problems in rural area. The increasing rate of load shading creates problems in rural area. Also in many villages of rural area the electricity has not reached till. The utilization of solar energy for electricity generation may reduce load shading problem, high cost of electricity and provides the solution for unelectrified villages. In this paper an attempt has been made to focus on development and evaluation of energy efficient eco friendly wooden casing LED based solar lantern. The most of the casing of the solar lantern are made of non disposable material like plastics and metal which creates environmental problems. The wood is available abundantly and cheaper than plastic and metal.. The main object of this paper is to design and develop energy efficient eco friendly wooden casing LED based solar lantern for farmer. This solar lantern is fabricated with the help of various components such as solar panel, charge controller, battery, LED driver, LED and wood casing. In this paper we have generated electrical power required for solar lantern by means of solar panel.

\section{Introduction}

Solar energy is the light and radiant heat from the Sun that influences Earth's climate, weather and sustains life. Solar power is sometimes used as a synonym for solar energy or more specifically to refer to electricity generated from solar radiation. Solar radiation is secondary resources like as wind and wave power, hydroelectricity and biomass account for most of the available flow of renewable energy on Earth.
Most of the farmers in villages used candle or kerosene lamp for lighting. Solar lantern provides higher quality light than the use of candle and kerosene lamp. Solar lantern use renewable energy with infinite supply which is cheaper than standard lamps. In addition, solar lantern is reduces health risk as kerosene lamps have a bad impact on human health. Solar lantern also used to provide street lighting in rural areas. In this case light emitting diode (LED) solar lanterns are usually used. 
The LED used in this lantern is energy efficient and require less power. The necessary power required for LED is supplied from the battery which is charged with the help of solar panel. Since LED required less power so that the battery which is charged on solar panel provides power to LED for more duration. This solar lantern can be easier for customers to install and maintain. Solar lantern can benefit owners with reduced maintenance cost and costs of electricity bills. This solar lantern can also be used in areas where there is no electrical grid or remote areas that lack a reliable electricity supply. The use of solar lantern improves education of students who live in households without electricity.

\section{Led based solar lantern (Fig. 1)}

The wooden casing of the LED solar lantern is developed. The different parts of the LED based solar lantern are shown in figure 2 . The main components of the lantern are solar panel, wooden casing, battery, LED bulb, charge controller, switch, LED Driver, wire. It was decided to use the power LED of $5 \mathrm{~W}$. The available solar panel of $12 \mathrm{w}$ was used. It was able to produce $17.25 \mathrm{~V} 0.7 \mathrm{~A}$ from solar panel configuration, $12 \mathrm{~V}$ sealed maintenance free battery was selected. Battery was weighing about $2.2 \mathrm{~kg}$. Battery was selected in such a way that it could be able to glow LED in the absence of the charging during night hour. Main challenge in the development of solar lantern was to design the casing. The wooden strips and wooden planks was selected which was intended to provide the necessary width and height. The wooden strips and planks be such that it should bear the weight of the internal circuit arrangement and battery. Casing should be light in the weight; it should be easy for transport, adjustment, dissembling and the assembling. So, after considering all requirements casing was developed which was able to bear the present load of battery, circuit. It was made such that it could be casing was easy for dissemble and assemble. Based on solar panel and battery, charge controller was selected. It was of the capacity $12 \mathrm{~V} 7 \mathrm{~A}$. The necessary connection of battery, panel, bulb, controller and switch were made. The developed solar lantern is shown in figure 3.

The developed LED solar lantern was tested for different parameters such as battery charging, battery discharging, lux intensity, panel voltage, panel current etc.

\section{Solar panel}

Solar panel which is converts the photon energy into the electrical energy. The solar panel was used to charge the battery. Solar panel was of $(34.5 \mathrm{~cm} \times 31.5 \mathrm{~cm})$. It was able to charge the battery of $12 \mathrm{~V} ; 7.2 \mathrm{Amp}$. It was oriented towards south at $45^{\circ}$ to receive maximum solar energy.

\section{LED driver}

LED driver is an electrical device which regulates the power to an LED. An LED Driver responds to the charging need of the LED, by providing a constant quantity of power to the LED

\section{Casing}

The wooden casing of size $27 \mathrm{~cm}$ height and width $22 \mathrm{~cm}$ was made to hold the battery and other internal components. There was switch, charging knob and charging indicators are provided on the wooden casing

\section{Battery}

$12 \mathrm{~V} 7.2 \mathrm{Ah}$ sealed maintenance free battery was used. The weight is approximately 2.2 $\mathrm{kg}$. Size of battery is $15 \mathrm{~cm} \times 6.5 \mathrm{~cm}$ Battery is 
selected on the basis of the use in Ampere Hours. Ampere hour indicates that load having particular ampere rating would discharge in specified hours.

\section{Charge controller}

The charge controller circuit is design and developed LED based solar lantern is as shown in figure 2 . The charge controller regulates the charge supply to battery. Thus it prevented the battery overcharging. The charge controller used for experiment was $12 \mathrm{~V}$ and 7Ampere. It is placed in between solar panel and battery. It is selected on the basis of the output of solar panel and capacity of the battery. So, here for $12 \mathrm{w}$ solar panel and $12 \mathrm{~V} 7.2 \mathrm{Ah}$ battery $\& 12 \mathrm{~V} 7 \mathrm{~A}$ charge controller is selected.

\section{Technical specification}

The technical specification of developed energy efficient eco friendly wooden casing LED based solar lantern are shown in table 1.

\section{Solar energy}

A solarimeter is a device designed to identify the radiation level of solar exposure on the Earth's surface. Solarimeter is placed at a flat surface where they can gain exposure to the full spectrum of electromagnetic radiation coming from the Sun. As the solar radiation impacts on the Earth's surface, the sensors within the device measure a full 180 degree radius around the instrument, finding changes in this radiation. The Behavior of current and voltage against Solar Intensity is shown in figure 4.

\section{Materials and Methods}

The evaluation of LED solar lantern was carried out. The experimental details are as follows:

\section{Testing of battery charging}

The battery charging characteristics of solar LED lantern was studied to determine the charging time and battery voltage rise or increase while lantern was in non- operating condition (Fig. 5).

The SPV panel was fully exposed in sunlight for battery charging. Three replications were conducted and average value was reported.

\section{Testing of battery discharging}

The battery discharging characteristics of solar lantern was studied to determine the discharge time and battery voltage reduction.

The fully charged battery was discharged by operating the lantern. The various parameters like time, battery voltage, battery current, were measured at an interval of 60 minutes. The voltage reduction was noted till the full discharge of battery. Three replications were conducted and average values were reported.

\section{Positioning of solar panel}

Solar panel output depends upon the two factors which are solar intensity and daily sunshine hours. Solar panel output varies with the positions of the panel.

For obtaining the maximum output solar panel should be south oriented in northern hemisphere with proper tilt angle which is generally adjusted to $45^{\circ}$.

\section{Testing of illumination level}

Illumination of LED bulb was constant throughout backup period. It was changed according to the distance, illumination was noted according to the distance vertical and horizontal from the center of lantern. 


\section{Results and Discussion}

The results obtained are as follows-

\section{Laboratory testing of LED solar lantern}

Laboratory testing of LED solar lantern was conducted to test different operating parameters like battery charging, discharging, and lux intensity.

\section{Battery charging with SPV panel of LED solar lantern}

The battery charging characteristics of LED solar lantern was studied to determine the charging time and battery voltage rise while lantern was in non operating condition. The SPV panel was fully exposed to sunlight for battery charging. The various parameters like panel voltage, panel current, battery voltage, solar intensity, battery current were measured.

It was observed that, the time required for charging of battery starting at 9.00am was $(10.8 \mathrm{v})$ found to be 8-9 hours to achieve full voltage of $14.2 \mathrm{v}$. The solar intensity was ranges from 373 to 690 during the test. The panel output voltage was varied from 18.3 to 19.3volt during test.

\section{Battery discharging of LED solar lantern}

The battery discharging characteristics of solar lantern was studied to determine the discharge time of battery. The various parameters recorded during the testing are summarized in appendix. The variation of battery voltage and battery current with time of LED solar lantern is shown in figure 6.

It was observed that the charged battery $(12.5 \mathrm{v})$ of LED solar lantern reduced gradually up to $\mathrm{m} 10.8 \mathrm{~V}$. The average operating time of LED solar lantern was found to be 10 hours.

\section{Illumination level test of LED solar lantern}

The lux intensity of Led solar lantern was studied to determine illumination level when detector is in horizontal to center point of bottom of lantern and illumination level when detector is at an angle of $90^{\circ}$ to the center point of the bottom of lantern. The variation of lux intensity with distance is shown in figure 7.

It was observed that lux intensity was 169.6 at a distance of 1 feet and decrease with the distance increase.

Table.1 Technical specification of LED solar lantern

\begin{tabular}{|c|c|c|}
\hline Sr. No. & Component & Specification \\
\hline 1. & Solar Photovoltaic Panel & $\begin{array}{l}12 \mathrm{~W}, 19.25 \mathrm{~V} \& 0.7 \mathrm{~A} \\
\text { Size: } 34.5 \mathrm{~cm} * 331.5 \mathrm{~cm}\end{array}$ \\
\hline 2. & Controller & $12 \mathrm{~V} 7 \mathrm{~A}$ \\
\hline 3. & Battery & $\begin{array}{c}\text { Voltage: } 12 \mathrm{~V} \\
\text { Capacity:7.2Ah }\end{array}$ \\
\hline 4. & Lantern casing & $\begin{array}{l}\text { Height: } 27 \mathrm{~cm} \\
\text { Width: } 22 \mathrm{~cm}\end{array}$ \\
\hline 5. & LED & $5 \mathrm{~W}$ \\
\hline 6. & Switch & 1 No. on/off \\
\hline 7. & Charging indicators & Two (green and red) \\
\hline
\end{tabular}


Figure.1 LED solar lantern

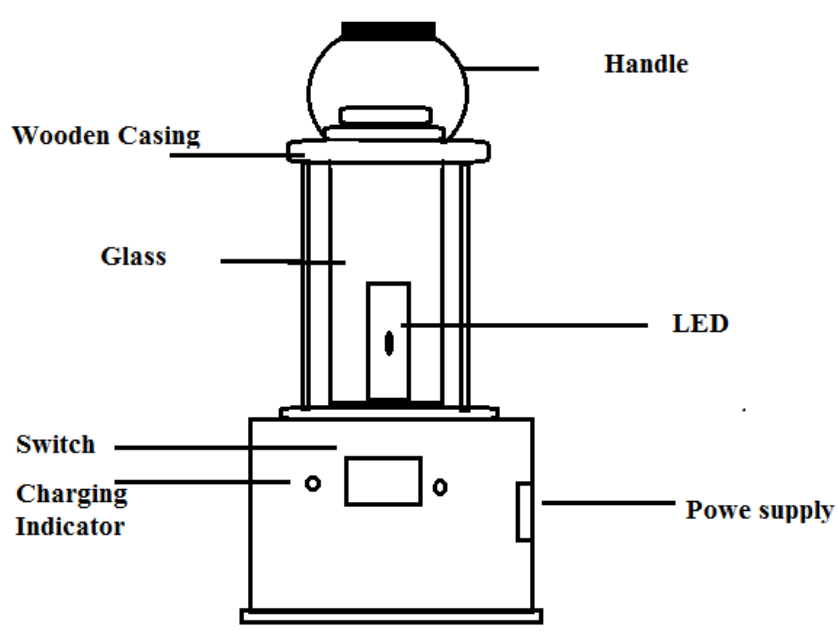

Figure.2 Charge controller circuit

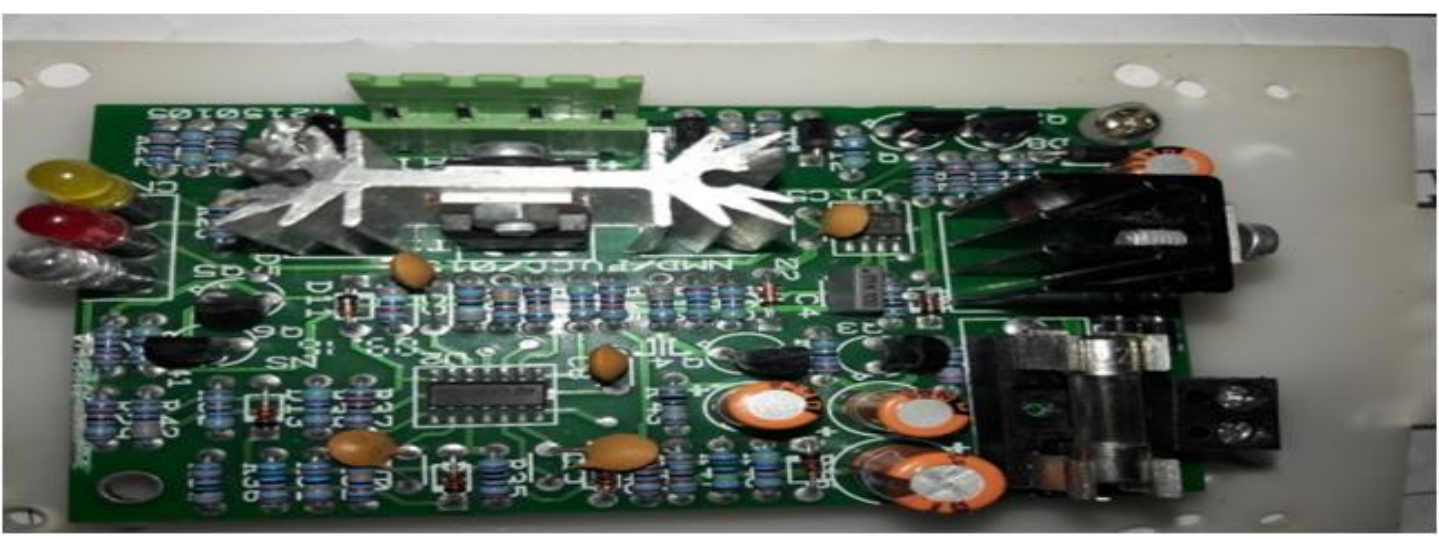

Figure.3 Developed efficient eco friendly wooden casing solar lantern

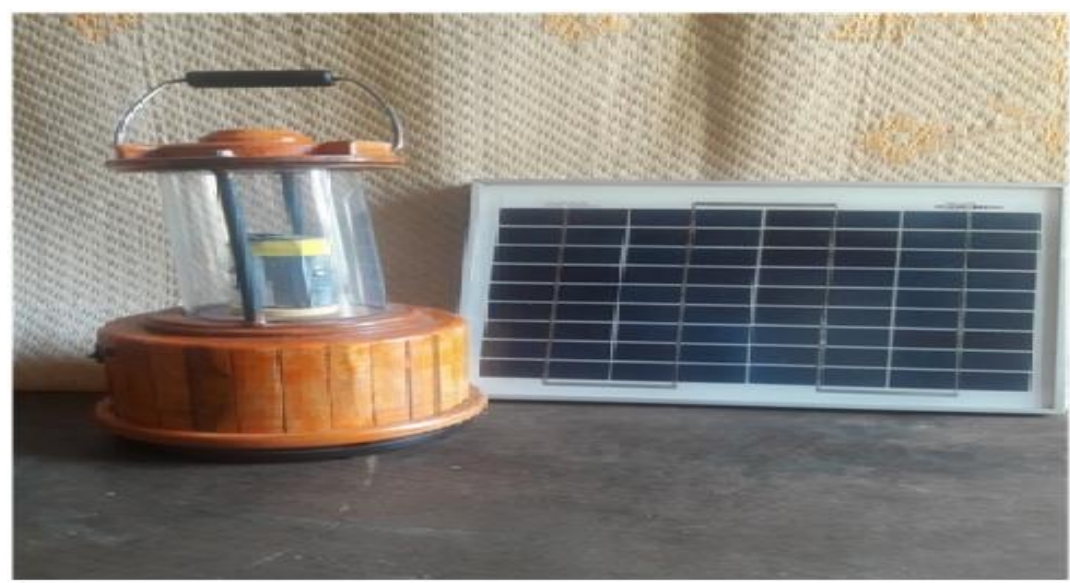


Figure.4 Behavior of current and voltage against Solar Intensity

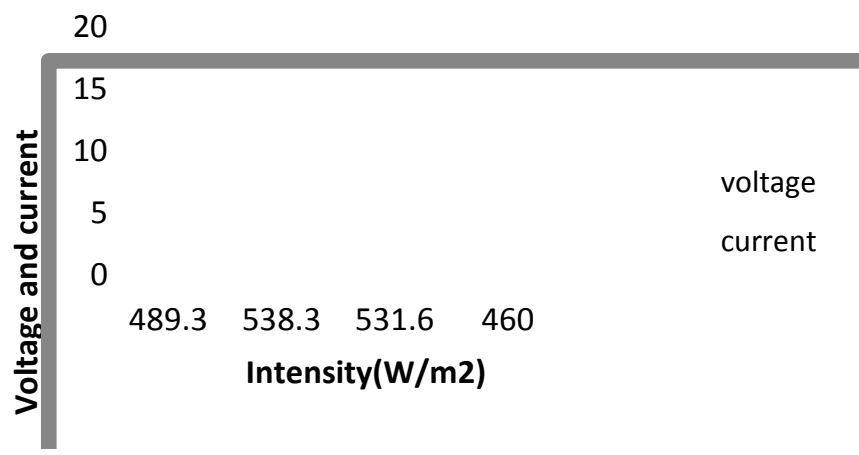

Figure.5 Battery Charging of LED Solar Lantern

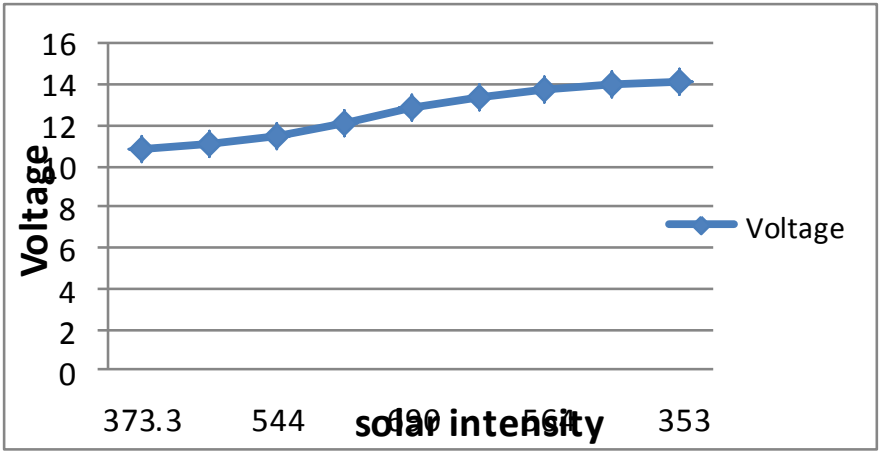

Figure.6 Battery Discharging of LED Solar Lantern

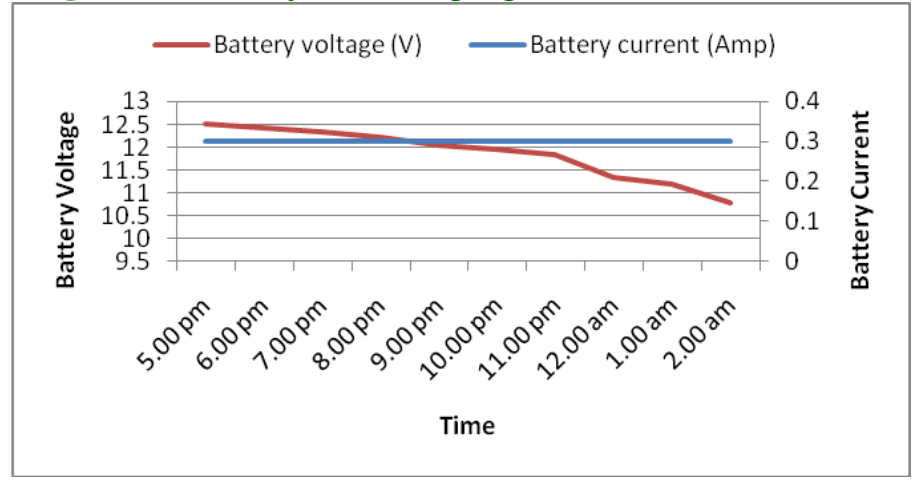

Figure.7 Illumination Level of LED Solar Lantern

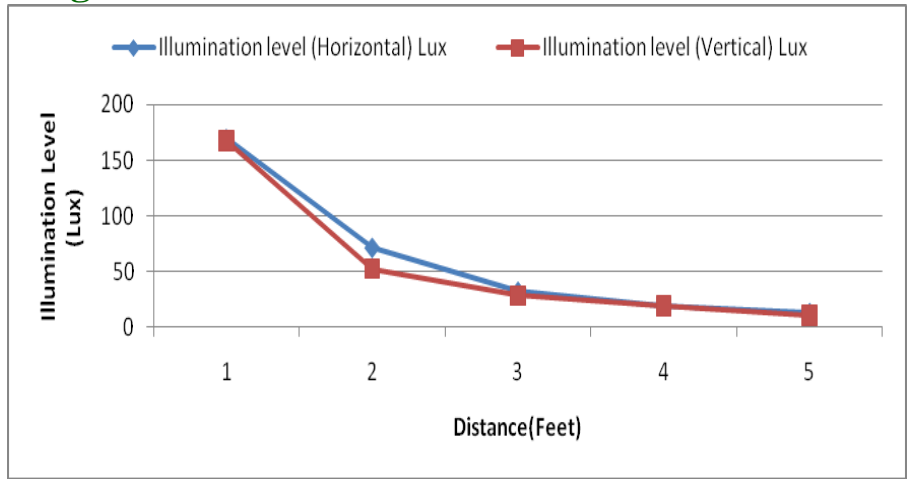


From the obtained results, it was concluded that,

1. Charging current and voltage of panel varied between $10 \mathrm{am}$ to $5 \mathrm{pm}$ and found to be $0.51 \mathrm{~A} 19.45 \mathrm{~V}$ at $10 \mathrm{am}$ and $0.31 \mathrm{~A}$ $17.90 \mathrm{~V}$ at $5 \mathrm{pm}$ respectively.

2. $9 \mathrm{hrs}$ are required to charge a battery of $12 \mathrm{~V} 7.2 \mathrm{Ah}$ by using $12 \mathrm{~W} 19.25 \mathrm{~V}$ solar panel.

3. $12 \mathrm{~V} 7.2 \mathrm{Ah}$ battery gives us $10 \mathrm{hr}$ battery backup, 5W LED was provided.

4. Highest illumination level 169.4 Lux was maintained at a distance of 1 feet is suitable for reading.

\section{References}

Bombale V.T., A.P. Magar, M.D. Abuj, P.G. Popleand P.R. Bhandari. 2010. Performance evaluation of SPV light traps cum lantern. International Journal of Agricultural Engineering, Vol.3 (1), pp: 55-58.

Chaurey A. and T.C. Kandpal. 2009. Solar lanterns for domestic lighting in India: viability of central charging station model. Renewable and Sustainable Energy Reviews Vol.14 page no.22662278 .
Dainis B. and I. Jurgena 2014. Research in Charging Parameters of Batteries. Engineering for Rural Development page no. 318-323

Iniyan S and K. Sumathy 2003. An optimal renewable energy model for various end-uses. Journal of Energy 25(6)563575

Kumar S., J. Diptilal, S.V. Charhate 2014. Green cooperative communication network using solar energy sources. American Journal of Engineering Research 03(05) 48-56

Lal S., P. Kumar, R. Rajeev. 2012. PV panel: Operation and Maintenance. International Journal of Engineering and Technology, Vol-24(1), pp: 76-79.

Mark Hankins 1997. Solar Lantern Market Study, Report prepared for "Kenya Photovoltaic Rural Energy Project"

Mkharjee D. 2007. solar lanterns were designed to replace hurricane lanterns for use in remote places where conventional electricity is not available. Fundamental of Renewable Energy System page no.111-114.

Thakur T. 2016. Solar Power Charge Controller. A Globle Journal of Researches in Engineering, 16(8)13-22.

\section{How to cite this article:}

Rajesh M. Dharaskar, A.G. Mohod, R.U. Sawant, N.A. Sail and Kolhe, P.R. 2019. Design and Development of Energy Efficient Eco Friendly Wooden Casing Led based Solar Lantern for Rural Area. Int.J.Curr.Microbiol.App.Sci. 8(02): 1704-1710. doi: https://doi.org/10.20546/ijcmas.2019.802.200 